Atıf için / For Citation: F. Eryılmaz, E. Türkmen, "Küçük Radikal Tümlenmiş Modüller", Süleyman Demirel Üniversitesi Fen Edebiyat Fakültesi Fen Dergisi, 15(1), 1-8, 2020.

\title{
Küçük Radikal Tümlenmiş Modüller
}

\author{
Figen ERYILMAZ ${ }^{* 1}$, Ergül TÜRKMEN ${ }^{2}$ \\ ${ }^{1}$ Ondokuz Mayıs Üniversitesi, Eğitim Fakültesi, Matematik ve Fen Bilimleri Eğitimi Bölümü, 55270 , \\ Samsun, Türkiye \\ ${ }^{2}$ Amasya Üniversitesi, Fen Edebiyat Fakültesi, Matematik Bölümü, 05100, Amasya, Türkiye \\ *yazışılan yazar e-posta: fyuzbasi@omu.edu.tr
}

(Alınış / Received: 05.09.2019, Kabul / Accepted: 11.12.2020, Yayımlanma / Published: 31.05.2020)

Özet: Bu çalışmada, küçük tümlenmiş modüller kullanılarak küçük radikal tümlenmiş modüller tanımlanmıştır ve bu modüllerin çeşitli özellikleri elde edilmiştir. Her küçük tümlenmiş modülün ve her zayıf radikal tümlenmiş modülün küçük radikal tümlenmiş modül olduğu açıktır. $\mathrm{Bu}$ önermelerin terslerinin doğru olmadığına dair örnekler verilmiştir. Küçük radikal tümlenmiş modüllerin sınıfinın sonlu toplamlarda ve bölüm modüllerinde korunduğu ispatlanmıştır. Bunun yanı sıra, sol kalıtsal halka üzerindeki bir $M$ modülünün $N \subseteq M$ olacak şekilde $N$ küçük modülü için $M$ nin küçük radikal tümlenmiş olması için gerek ve yeter koşulun $\frac{M}{N}$ bölüm modülünün küçük radikal tümlenmiş olması gerektiği gösterilmiştir. Ayrıca sol kalıtsal $R$ halkası için $R$ sol $R$-modülünün küçük radikal tümlenmiş olması için gerekli ve yeterli koşulun $\frac{R}{\operatorname{Rad}(R)}$ bölüm modülünün küçük tümlenmiş olması gerektiği gösterilmiştir. Ayrıca, lokal Dedekind bölgesi üzerinde her küçük radikal tümlenmiş modülün radikal tümlenmiş olduğu ispatlanmıştır.

Anahtar kelimeler: Küçük modül, Küçük tümleyen, Radikal

\section{Small Radical Supplemented Modules}

\begin{abstract}
In this paper, we introduce the notion of small radical supplemented modules, which is adapted from small supplemented modules and obtain the various properties of these modules. It is clear that every small supplemented module and weakly radical supplemented module are small radical supplemented modules. In this study, we give examples for which the converses of these propositions need not to be true. We prove that the class of small radical supplemented modules is closed under finite sums and factor modules. Moreover, it is shown that a submodule $N$ of $M$ which is small in $M$ is small radical supplemented if and only if $\frac{M}{N}$ is small radical suplemented where $M$ is a module over any left hereditary ring. Nevertheless, we show that for a left hereditary ring $R,{ }_{R} R$ is small radical supplemented if and only if $\frac{R}{\operatorname{Rad}(R)}$ is small supplemented. Also, we prove that every small radical supplemented module over a local Dedekind domain (DVR) is radical supplemented.
\end{abstract}

Key words: Small module, Small supplement, Radical 


\section{Giriș}

Bu makalede, bütün halkalar birimli ve birleşmeli, bütün modüller üniter sol $R$-modül olarak alınacaktır. $R$ bir halka ve $M$ bir $R$-modül olsun. $M$ modülünün $N$ alt modülü $N \subseteq M$ ile gösterilir. $L \subseteq M$ olmak üzere $M$ modülünün sıfırdan farklı her $N$ alt modülü için $L \cap N \neq 0$ ise $L$ alt modülüne $M$ modülünün büyük alt modülü denir ve $L \triangleleft M$ ile gösterilir. $S \subseteq M$ olmak üzere $M$ modülünün her $L$ öz alt modülü için $M \neq S+L$ ise $S$ alt modülüne $M$ modülünün küçük alt modülü denir ve $S \square M$ ile gösterilir [8]. Eğer $M$ bazı modüllerin küçük alt modülü ise $M$ modülüne küçük modül denir [5]. Yine bu çalışmadaki Teorem 1'de $E(M), M$ modülünün injektif bürümü olmak üzere $M$ modülünün küçük modül olması için gerekli ve yeterli koşulun $M$ modülünün $E(M)$ nin küçük alt modülü olması gerektiği gösterilmiştir. $\operatorname{Rad}(M)$ sembolüyle $M$ modülünün bütün maksimal alt modüllerinin arakesiti gösterilecektir ve buna $M$ modülünün radikali denir.

$M$ bir $\quad R$-modül ve $N \subseteq M$ olsun. $\quad M=N+L$ şeklindeki $\quad M$ modülünün $L$ alt modüllerinin minimali olan $K$ alt modülüne, $N$ alt modülünün tümleyeni denir. $K$ alt modülünün $N$ alt modülünün tümleyeni olması için gerek ve yeter koşul $M=N+K$ ve $N \cap K \square K$ olmasıdır. Eğer $M=N+K$ ve $N \cap K \square M$ ise $K$ alt modülüne $N$ alt modülünün zaylf tümleyeni denir. Eğer $M$ modülünün her alt modülü (zayıf) tümleyene sahip ise $M$ modülüne (zayıf) tümlenmiş modül denir, [6], [8]. Artin modüller tümlenmiş ve tümlenmiş modüller zayıf tümlenmiştir. Eğer $\operatorname{Rad}(M), M$ modülünde tümleyene sahip ise $M$ modülüne radikal tümlenmiştir denir [9]. $\mathrm{Bu}$ modüller tümlenmiş modüllerin bir öz genelleştirmesidir. Eğer $M$ modülünün $\operatorname{Rad}(M) \subseteq N$ olacak şekildeki her $N$ alt modülü $M$ modülünde bir tümleyene (zayıf tümleyene) sahip ise $M$ modülüne güçlü radikal tümlenmiş (zaylf radikal tümlenmiş) modül denir $[3,7]$. Özel olarak [7] nolu kaynaktaki Sonuç 3.3 de lokal Dedekind bölgesi üzerindeki zayıf radikal tümlenmiş modüllerin (güçlü) radikal tümlenmiş olduğu gösterilmiştir.

[1] nolu makalede zayıf tümlenmiş modüller küçük tümlenmiş modüllere genelleştirilmiştir. $M$ modülünün her $U$ alt modülü bir $V$ küçük tümleyene sahip ise yani $M=U+V$ ve $U \cap V$ küçük modül ise $M$ modülüne küçük tümlenmiştir denir. Aynı makalede bu modüllerin çeşitli özellikleri elde edilmiş ve lokal Dedekind bölgesi üzerinde küçük tümlenmiş modüllerin yapısı araştırılmıştır.

Biz bu çalışmada yukarıdaki tanımlardan yola çıkarak modülün radikalini içeren her alt modülü küçük tümleyene sahip modülleri tanımladık. Eğer $M$ modülünün $\operatorname{Rad}(M) \subseteq U$ olacak şekildeki her $U$ alt modülü $M$ modülünde bir küçük tümleyene sahip ise $M$ modülüne küçük radikal tümlenmiş modül denir.

$\mathrm{Bu}$ çalışmada küçük radikal tümlenmiş modüllerin çeşitli özellikleri araştırılmıştır. Küçük radikal tümlenmiş modüllerin sınıfının sonlu toplamlar ve bölüm modülleri altında kapalı olduğu gösterilmiştir. Eğer $M$ modülü küçük radikal tümlenmiş ise $\frac{M}{Z^{*}(M)}$ bölüm modülünün yarı basit olduğu ispatlanmıştır. Ayrıca, sol kalıtsal $R$ halkası üzerindeki her sol $R$-modülün küçük radikal tümlenmiş olması için gerekli ve yeterli koşulun $\frac{R}{\operatorname{Rad}(R)}$ bölüm modülünün küçük tümlenmiş olması gerektiği gösterilmiştir. Bunun yanı sıra, lokal Dedekind bölgesi (DVR) üzerindeki her küçük radikal tümlenmiş modülün radikal tümlenmiş olduğu ispatlanmıştır. 


\section{Küçük Radikal Tümlenmiş Modüller}

Her küçük tümlenmiş modülün küçük radikal tümlenmiş modül olduğu açıktır. Ama tersi her zaman doğru değildir. Yani küçük radikal tümlenmiş modülün küçük tümlenmiş modül olması gerekmez. Aşağıda bu duruma bir örnek verilmiştir.

$M$ bir modül olmak üzere eğer $\operatorname{Rad}(M)=M$ ise $M$ modülüne radikal modül denir.

Önerme 2.1. Her radikal modül küçük radikal tümlenmiştir.

Isspat: $M$ bir radikal modül olsun. [3, Önerme 2.2] gereği $M$ zayıf radikal tümlenmiş modül olup $M$ küçük radikal tümlenmiştir.

$P(M), M$ modülünün bütün radikal alt modüllerinin toplamı olmak üzere $P(M), M$ modülünün en büyük radikal alt modülüdür.

Sonuç 2.2. Her $M$ modülü için $P(M)$ küçük radikal tümlenmiştir.

Ispat: Önerme 2.1 den açıktır.

Örnek 2.3. $R$ lokal Dedekind bölgesi ve $K, R$ nin kesir cismi olmak üzere $K$ sol $R$ modülü injektif olsun. Ayrıca $\mathbb{Z}^{+}$pozitif tam sayılar kümesi olmak üzere $M={ }_{R}\left(\frac{K}{R}\right)^{\mathbb{Z}^{+}}$ sol $R$-modülünü göz önüne alalım. $R$ Noetherian olduğundan $M$ injektiftir. [2, Önerme 4.4] gereği $M$ radikal modül olup Önerme 2.1 den $M$ küçük radikal tümlenmiştir. Diğer taraftan $M$ küçük tümlenmiş değildir [1, Önerme 6.7].

Her zayıf radikal tümlenmiş modül küçük radikal tümlenmiştir. Aşağıda tersinin daima doğru olmadığına dair bir örnek verilmiştir. Sıfır radikale sahip her zayıf radikal tümlenmiş modül yarı basittir.

Örnek 2.4. Yarı basit olmayan $M==_{\square} \square$ modülü verilsin. $\operatorname{Rad}(M)=0$ olup $M, E(M)=\square$ da küçüktür. Dolayısıyla $M$ modülünün her alt modülü küçük modüldür. $\mathrm{O}$ halde $M$ küçük (radikal) tümlenmiştir. Diğer taraftan $M$ zayıf radikal tümlenmiş değildir.

Modüller ile ilgili aşağıdaki diyagram verilebilir:

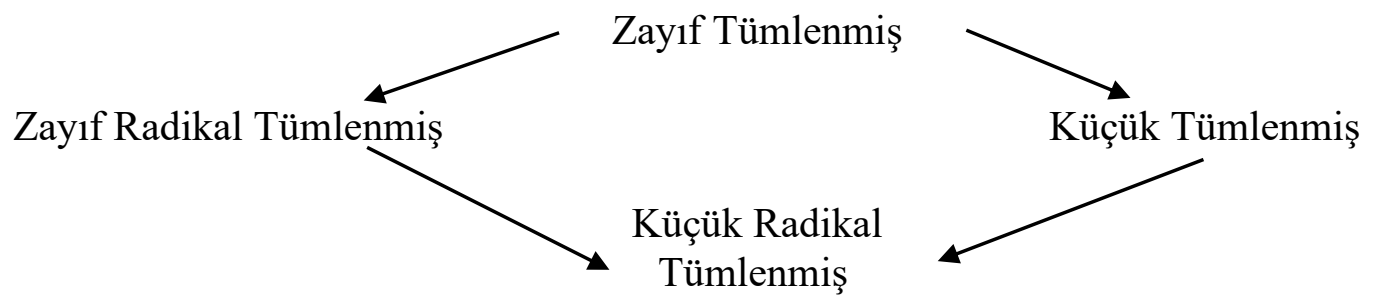

Önerme 2.5. $M$ küçük radikal tümlenmiş modül olmak üzere $\operatorname{Rad}(M) \square M$ olsun. Bu takdirde $M$ küçük tümlenmiştir.

İspat: $U \subseteq M$ olsun. Hipotez gereği $\operatorname{Rad}(M)+U, M$ de $V$ küçük tümleyenine sahiptir. Buradan $M=(\operatorname{Rad}(M)+U)+V$ yaz1labilir ve $(\operatorname{Rad}(M)+U) \cap V, M$ 
modülünde küçük modüldür. $\operatorname{Rad}(M) \square M$ olduğundan $M=U+V$ olur. Ayrıca $U \cap V \subseteq(\operatorname{Rad}(M)+U) \cap V$ dir. [5, Teorem 2] gereği $U \cap V, M$ modülünde küçük modül olup $V, M$ de $U$ alt modülünün küçük tümleyenidir. Sonuç olarak $M$ küçük tümlenmiştir.

$M$ modülünün her öz alt modülü $M$ modülünün bir maksimal alt modülünde içeriliyorsa $M$ ye eş atomik modül denir [4]. Buna göre her sonlu üretilmiş modül eş atomiktir.

Sonuç 2.6. $M$ eş atomik modül olsun. $M$ modülünün küçük radikal tümlenmiş olması için gerek ve yeter koşul $M$ modülünün küçük tümlenmiş olmasıdır.

Isspat: Her eş atomik modül küçük radikale sahip olduğundan Önerme 2.5 gereği açıtır.

$M$ modülünün $Z^{*}(M)=\{m \in M \mid R m \square M\}$ alt modülünü ele alalım. $\operatorname{Rad}(M), M$ modülünün küçük alt modüllerinin toplamı olduğundan $\operatorname{Rad}(M) \subseteq Z^{*}(M)$ dir. $Z^{*}(M)=M \cap \operatorname{Rad}(E(M))$ olduğunu görmek kolaydır. Ayrıca $Z^{*}(M)=M$ olması için gerek ve yeter koşul $M \subseteq \operatorname{Rad}(E(M))$ olmasıdır. Ĕğer $Z^{*}(M)=M$ ise $M$ modülüne Rad-küçük modül denir. $Z^{*}\left(Z^{*}(M)\right)=Z^{*}(M)$ olduğundan $Z^{*}(M), M$ modülünün en geniş Rad-küçük alt modülüdür. Küçük modüllerin Rad-küçük modül olduğu açıktır. Ayrıca eş atomik Rad-küçük modül küçük modüldür.

Teorem 2.7. $M$ bir modül ve $Z^{*}(M) \sqcap M$ olsun. Bu takdirde aşağıdakiler denktir.

(1) $M$ küçük radikal tümlenmiştir.

(2) $M$ küçük tümlenmiştir.

(3) $M$ zayıf tümlenmiştir.

(4) $M$ zayif radikal tümlenmiştir.

Íspat: $Z^{*}(M) \square M$ olduğundan $\operatorname{Rad}(M)=Z^{*}(M)$ olup $\operatorname{Rad}(M) \square M \operatorname{dir}$.

$(1) \Rightarrow(2)$ Önerme 2.5 den açıktır.

(2) $\Rightarrow$ (3) $U \subseteq M$ olsun. Hipotez gereği $M=U+V$ ve $U \cap V, M$ de küçük modül olacak şekilde $M$ modülünün $V$ alt modülü vardır. Böylece $U \cap V \subseteq Z^{*}(M)$ olup [4, Önerme 5.1.3(b)] gereği $U \cap V \square M$ dir. Sonuç olarak $M$ zayıf tümlenmiştir.

(3) $\Rightarrow$ (4) ve (4) $\Rightarrow$ (1) açıktır.

Önerme 2.8. $M$ küçük radikal tümlenmiş modül ise $\frac{M}{Z^{*}(M)}$ yarı basittir.

İspat: Kabul edelim ki $M$ küçük radikal tümlenmiş modül ve $Z *(M) \subseteq U \subseteq M$ olsun. $\operatorname{Rad}(M) \subseteq Z^{*}(M)$ olduğundan $\operatorname{Rad}(M) \subseteq U$ olur. Kabulümüz gereği $M=U+V$ ve $U \cap V, M$ modülünde küçük modül olacak şekilde $M$ modülünün $V$ alt modülü vardır. Dolayısıyla $U \cap V \subseteq Z^{*}(M)$ dir. Buradan

$$
\frac{M}{Z^{*}(M)}=\frac{U}{Z^{*}(M)} \oplus\left(\frac{V+Z^{*}(M)}{Z^{*}(M)}\right)
$$


olup $\frac{M}{Z^{*}(M)}$ yarı basittir.

Önerme 2.9. Küçük radikal tümlenmiş modülün homomorfik görüntüsü de küçük radikal tümlenmiştir.

Ispat: $\quad N \subseteq M \quad$ için $\quad \operatorname{Rad}\left(\frac{M}{N}\right) \subseteq \frac{U}{N} \subseteq \frac{M}{N} \quad$ olsun. $\quad \frac{\operatorname{Rad}(M)+N}{N} \subseteq \operatorname{Rad}\left(\frac{M}{N}\right) \subseteq \frac{U}{N}$ olduğundan $\operatorname{Rad}(M) \subseteq U$ olur. Kabulümüz gereği $M=U+V$ ve $U \cap V, M$ de küçük modül olacak şekilde $M$ modülünün $V$ alt modülü vardır. Buradan $\frac{M}{N}=\frac{U}{N}+\frac{(V+N)}{N}$ elde edilir. $\pi: M \rightarrow \frac{M}{N}$ kanonik epimorfizmasını göz önüne alalım. [5, Teorem 2] gereği $\pi(U \cap V)=\frac{(U \cap V)+N}{N}$ küçük modül olup ispat tamamlanır.

Sonuç 2.10. Eğer $M$ küçük radikal tümlenmiş modül ise $\frac{M}{\operatorname{Rad}(M)} \quad$ küçük tümlenmiştir.

Ispat: Bir önceki önerme gereği $\frac{M}{\operatorname{Rad}(M)}$ küçük radikal tümlenmiş olup $\operatorname{Rad}\left(\frac{M}{\operatorname{Rad}(M)}\right)=0$ olduğundan Önerme 2.5 göz önüne alınırsa $\frac{M}{\operatorname{Rad}(M)}$ küçük tümlenmiştir.

Küçük radikal tümlenmiş modüllerin sonlu toplamlarının küçük radikal tümlenmiş olduğunu göstermek için önce aşağıdaki önermeyi verelim.

Önerme 2.11. $M$ bir modül, $M_{1} \subseteq M$ ve $U, M$ modülünün $\operatorname{Rad}(M) \subseteq U$ olacak şekildeki alt modülü olsun. Eğer $M_{1}$ küçük radikal tümlenmiş ve $M_{1}+U, M$ de küçük tümleyene sahip ise $U, M$ de küçük tümleyene sahiptir.

Íspat: Hipotez gereği $M=\left(M_{1}+U\right)+V$ ve $\left(M_{1}+U\right) \cap V, M$ de küçük modül olacak şekilde $M$ modülünün $V$ alt modülü vardır. $\operatorname{Rad}\left(M_{1}\right) \subseteq \operatorname{Rad}(M) \subseteq U$ olduğundan $\operatorname{Rad}\left(M_{1}\right) \subseteq M_{1} \cap(U+V)$ olur. Dolayisiyla $\quad M_{1}=M_{1} \cap(U+V)+K$ ve $(U+V) \cap K, M_{1}$ de küçük modül olacak şekilde $M_{1}$ modülünün $K$ alt modülü vardır. Buradan

$$
M=\left(M_{1}+U\right)+V=\left[M_{1} \cap(U+V)+K+U\right]+V=U+(V+K)
$$

olup [5] çalışmasındaki Teorem 2(Sonuç) gereği

$$
U \cap(V+K) \subseteq(U+V) \cap K+(U+K) \cap V \subseteq(U+V) \cap K+\left(U+M_{1}\right) \cap V
$$


küçük modül olur. Sonuç olarak $V+K, U$ modülünün $M$ de küçük tümleyenidir.

Önerme 2.12. $M_{1}$ ve $M_{2}$ küçük radikal tümlenmiş modüller olmak üzere $M=M_{1}+M_{2}$ olsun. Bu takdirde $M$ küçük radikal tümlenmiştir.

Ispat: $\operatorname{Rad}(M) \subseteq U \subseteq M$ olsun. $0, M_{1}+M_{2}+U$ toplamının $M$ de küçük tümleyeni olduğundan bir önceki önerme gereği $M_{1}+U, M$ de küçük tümleyene sahip olur. Bir önceki önerme tekrar kullanılırsa $U$ nun $M$ de küçük tümleyene sahip olduğu elde edilir.

Sonuç 2.13. Küçük radikal tümlenmiş modüllerin sınıfı sonlu toplamlar altında kapalidir.

Önerme 2.14. $R$ sol kalitsal halka olmak üzere $M$ bir $R$ - modül ve $N, M$ modülünün küçük modülü olsun. Bu takdirde $M$ modülünün küçük radikal tümlenmiş olması için gerek ve yeter koşul $\frac{M}{N}$ bölüm modülünün küçük radikal tümlenmiş olmasidir.

İspat: $(\Rightarrow)$ Önerme 2.9 dan açıktır.

$(\Leftarrow) \quad \frac{M}{N} \quad$ bölüm modülü küçük radikal tümlenmiş modül olmak üzere $\operatorname{Rad}(M) \subseteq U \subseteq M$ olsun. Bu takdirde $\frac{U+N}{N}, \frac{M}{N}$ de $\frac{V}{N}$ küçük tümleyenine sahiptir. Buradan $M=U+V$ olup $\frac{(U+N)}{N} \cap \frac{V}{N}=\frac{(U \cap V)+N}{N} \cong \frac{U \cap V}{U \cap N}$ küçük modül olur. $N$ küçük modül olduğundan [5, Teorem 2] gereği $U \cap N$ küçük modüldür. Yine aynı kaynaktaki Teorem 3 gereği $U \cap V$ küçük modül olur. Böylece $M$ küçük radikal tümlenmiştir.

Teorem 2.15. $R$ sol kalıtsal halka olmak üzere $M$ bir $R$ - modül ve $N, M$ modülünün küçük tümleyene sahip alt modülü olsun. Eğer $N$ ve $\frac{M}{N}$ modülleri küçük radikal tümlenmiş modüller ise $M$ de küçük radikal tümlenmiştir.

Ispat: $K, M$ de $N$ modülünün küçük tümleyeni yani $M=N+K$ ve $N \cap K$ küçük modül olsun. Önerme 2.14 gereği $\frac{M}{N \cap K}$ nın küçük radikal tümlenmiş olduğunu gösterirsek ispat tamamlanır. $\quad M=N+K$ olduğundan $\frac{M}{N \cap K}=\frac{N}{N \cap K} \oplus \frac{K}{N \cap K}$ yazılır. $N$ küçük radikal tümlenmiş olduğundan Önerme 2.9 gereği $\frac{N}{N \cap K}$ küçük radikal tümlenmiştir. Buradan $\frac{K}{N \cap K} \cong \frac{M}{N}$ küçük radikal tümlenmiş olup Önerme 2.12 gereği $\frac{M}{N \cap K}$ küçük radikal tümlenmiştir. 
$M$ bir modül, $m \in M, N \subseteq M$ ve $m+N=\{m+x \mid x \in N\}$ kümesi $M$ nin bir yan sınıfı olmak üzere $\left\{C_{i} \mid i \in I\right\}, M$ nin yan sınıflarının boş kümeden farklı bir ailesi olsun. Eğer $I$ nın boş kümeden farklı her sonlu $F$ alt kümesi için $\bigcap_{i \in F} C_{i}$ boş kümeden farklı ise $\left\{C_{i} \mid i \in I\right\}$ yan sınıflarının ailesi sonlu kesişim özelliğine sahiptir denir. Yan sınıflarının sonlu kesişim özelliğine sahip boş kümeden farklı her $\left\{C_{i} \mid i \in I\right\}$ ailesi için $\bigcap_{i \in I} C_{i}$ boş kümeden farklı ise $M$ modülüne lineer kompakttır denir. Lineer kompakt modüller tümlenmiştir [8].

Sonuç 2.16. $R$ sol kalitsal halka olmak üzere $M$ bir $R$ - modül ve $N, M$ modülünün lineer kompakt alt modülü olsun. Bu takdirde $M$ modülünün küçük radikal tümlenmiş olması için gerek ve yeter koşul $\frac{M}{N}$ modülünün küçük radikal tümlenmiş olmasıdır.

İspat: [8] çalışmasındaki 41.10(1) gereği $N$ her genişlemesinde küçük tümleyene sahip olup Teorem 2.15 den ispat açıktır.

Artin modüller lineer kompakt olduğundan aşağıdaki sonucu verebiliriz.

Sonuç 2.17. $R$ sol kalıtsal halka olmak üzere $M$ bir $R$-modül ve $N, M$ modülünün Artin alt modülü olsun. Bu takdirde $M$ modülünün küçük radikal tümlenmiş olması için gerek ve yeter koşul $\frac{M}{N}$ modülünün küçük radikal tümlenmiş olmasıdır.

Sonuç 2.18. $R$ sol kalıtsal halkası için aşağıdakiler denktir:

(1) $R$ sol $R$-modülü küçük tümlenmiştir.

(2) $R$ sol $R$-modülü küçük radikal tümlenmiştir.

(3) $\frac{R}{\operatorname{Rad}(R)}$ küçük tümlenmiştir.

İspat: $(1) \Rightarrow(2)$ Açıtır.

(2) $\Rightarrow$ (3) Sonuç 2.10 dan açıtıtır.

(3) $\Rightarrow$ (1) $\operatorname{Rad}(R)$ küçük $R$-modül olduğundan Önerme 2.14 gereği $R$ sol $R$ modülü küçük radikal tümlenmiştir. Önerme 2.5 den $R$ sol $R$-modülü küçük tümlenmiştir.

Son olarak lokal Dedekind bölgesi üzerinde radikal tümlenmiş modüller ile küçük radikal tümlenmiş modüllerin çakıştığını aşağıdaki teoremde gösterelim.

Teorem 2.19. $R$ lokal Dedekind bölgesi ve $M$ bir $R$ - modül olsun. Bu takdirde aşağıdaki ifadeler denktir:

(1) $M$ küçük radikal tümlenmiştir.

(2) $\operatorname{Rad}(M), M$ de küçük tümleyene sahiptir.

(3) $\operatorname{Rad}(M), M$ de zayıf tümleyene sahiptir.

(4) $M$ zayıf radikal tümlenmiştir. 
(5) $M$ radikal tümlenmiştir.

(6) $M$ modülünün indirgenmiş kısmı $T(M)$ sınırlı ve $\frac{N}{\operatorname{Rad}(N)}$ sonlu üretilmiş olmak üzere $M=T(M) \oplus N$ dir.

İspat: $(1) \Rightarrow(2)$ ve $(5) \Rightarrow$ (1) Açıktır.

$(2) \Rightarrow(3)[1$, Önerme 6.2].

$(3) \Rightarrow(4)$ ve $(4) \Rightarrow(5)[7$, Sonuç 3.3].

$(5) \Rightarrow(6)[9$, Önerme 3.1]

\section{Araştırmacıların Katkı Oranı Beyanı}

Figen ERYILMAZ: Araştırma, Kavramsallaştırma, Doğrulama, İnceleme ve Düzenleme, Biçimsel Analiz, Proje Yönetimi, Orijinal Taslak Yazımı

Ergül TÜRKMEN: Araştırma, Metodoji, Doğrulama, İnceleme ve Düzenleme, Veri İyileştirme, Proje Yönetimi

\section{Destek ve Teșekkür Beyanı}

$\mathrm{Bu}$ çalışmanın yazarları olarak herhangi bir destek ve teşekkür beyanımız bulunmadığını bildiririz.

\section{Çatışma Beyanı}

Bu çalışmanın yazarları olarak herhangi bir çatışma beyanımız bulunmadığını bildiririz.

\section{Etik Kurul Onayı ve/veya Aydınlatılmış Onam Bilgileri}

$\mathrm{Bu}$ çalışmanın yazarları olarak herhangi bir etik kurul onayı ve/veya aydınlatılmış onam bilgileri beyanımız bulunmadığgnı bildiririz.

\section{Kaynakça}

[1] R. Alizade, E.Büyükaş1k, and Y. Durgun, "Small supplements, weak supplements and proper classes," Hacettepe Journal of Mathematics and Statistics, 45(3), 449-461, 2016.

[2] R. Alizade, G. Bilhan, and P. F. Smith, "Modules whose maximal submodules have supplements," Communications in Algebra, 29(6), 2389-2405, 2001.

[3] E. Büyükaşı and E. Türkmen, "Strongly radical supplemented modules," Ukranian Mathematical Journal, 106, 25-30, 2011.

[4] F. Kasch, Modules and Rings, Academic Press Inc., 1982.

[5] W.W. Leonard, "Small modules," Proc. Amer. Math. Soc., 17, 527-531, 1966.

[6] C. Lomp, "Semilocal modules and rings," Communications in Algebra, 4, 1921-1935, 1999.

[7] B. Nişancı Türkmen and E. Türkmen, "On a generalization of weakly supplemented modules," $A n$. Ştiint.Univ. Al. I. Cuza Iaşi. Mat. (N.S.), LXIII (2), 441-448, 2017.

[8] R. Wisbauer, Foundations of Modules and Rings Theory, Gordon and Breach, 1991.

[9] H. Zöschinger, "Moduln, die in jeder erweiterung ein komplement haben," Math. Scand., 35, $267-$ 287, 1974. 